\title{
INTERVIEW WITH RENÉ D. FLORES
}

\author{
INTERVIEW CONDUCTED BY:
}

ERIN ADAMSON

University of Kansas

\section{INTERVIEW TRANSCRIBED BY:}

\author{
ELYSE NEUMANN \\ University of Kansas
}

\begin{abstract}
Dr. René D. Flores, 2018 Blackmar Lecturer, is the Neubauer Family Assistant Professor of Sociology at the University of Chicago. His primary research interests are in the fields of international migration, race and ethnicity, and social stratification. His work has appeared in the American Sociological Review, American Journal of Sociology, Social Forces, and Social Problems.
\end{abstract}

\begin{abstract}
ADAMSON: It's a Wednesday, March $14^{\text {th }}$, and I'm talking to René Flores. Thanks for joining us. I spent some time reading through your papers last night. So, you've covered effects of antiimmigration legislation in Arizona, gun sales, racialization of immigrants in Spain, racial disparities in health care. I'm interested to hear how you describe your sociology and what are the main themes that kind of run through it all, that connect your research agenda.
\end{abstract}

FLORES: First of all, thank you for inviting me here. I think that's a great question. I try to focus on the social boundaries that emerge around particular populations. In this case, I'm interested in immigrants, but also in ethnic and racial minorities. I want to understand how these boundaries emerge, what explains them, and what they are made of. But also, what are the consequences of these boundaries? I think that's the guiding principle in all my research. Some of these boundaries could be legality, which I think it's a huge factor that is shaping the lives of millions of individuals in the U.S., 
including their U.S.-born offspring. I've also looked at the effect of skin color on different life outcomes, so that's a different kind of boundary that you can actually study, for example. I'm also interested in how these boundaries relate to inequality. Why it is that particular populations end up in very disparate situations? But ultimately, and maybe this is why I identify myself as an analytical sociologist, I really care about understanding not only effects and correlations but also what is driving these effects and correlations. What are the mechanisms that are involved? And sometimes I feel a little bit like a detective, in the sense that if I find a correlation first I try to determine if it's an actual casual effect. If that's the case, what's causing it in the first place? And like a persistent hound, I start digging in to uncover all the potential mechanisms involved in a very obsessive, neurotic way, actually. So, that's how I see what I'm trying to do.

ADAMSON: Uh huh, in a way that works for you, though.

FLORES: [laughing] Hopefully, I don’t know.

ADAMSON: It seems clear.

FLORES: That's not what a reviewer said, though, for an article that got rejected two days ago. You know, sometimes...

ADAMSON: They didn't like it.

FLORES: Right.

ADAMSON: So, I'm also wondering how your biography impacts what you're interested in and how you're shaping your career, how you're kind of setting up your research.

FLORES: Another great question [laughs]. So I was born in Mexico City, which is not a traditional sending area for immigrants. I actually didn't know any immigrants growing up and I never thought I'd become one myself. I come from a professional background, but I ended up moving to the U.S., to California, for political reasons. I was not part of the historic traditional migration wave that came 
from specific communities in the Mexican hinterland. So a lot of those histories, a lot of those political struggles were not readily available to me. I had to learn them in the field, by meeting people. I learned of the difficulties of not having documentation, the plight of working mothers who hold multiple jobs and are just trying to survive. So I really got to know this history from the perspective of immigrants, not only from Latin America. Actually, some of my closest friends in California were refugees from Poland, who had been involved in the solidarity movement. I also met Chicano, black, and queer activists; I got to know a lot these progressive groups that I had never encountered before. In Mexico City I was involved in politics, but from a more conservative perspective. My family's conservative, but here I was exposed to a very different kind of reality and I was very lucky to meet folks that exposed me to different ways of thinking.

ADAMSON: And you were a university student at the time? Or...when you were meeting these folks?

FLORES: I was. I was attending San Diego City College, which was a little bit of a lifestyle. We would do a lot of art and media projects. We would play music and talk about politics non-stop. I was also doing community radio and activism. I did different types of activism including workers' rights, immigrant rights, and community media access. I did that for several years, but I would also save money to travel around the world. During those years, I was quite interested in changing things, but I was also very interested in trying to get a better understanding of how things came to be, because I knew there were all these larger forces that were shaping the lives of all these folks, right?

ADAMSON: Yeah.

FLORES: At some point, I flirted with the idea of becoming a journalist. I went to Berkeley, and I worked at the school of journalism there and I was travelling a lot, doing international reporting. I liked the possibility of being able to be in the front row of history. I liked getting to know different types of folks, writing stories about them, but there were three things about journalism that 
made think twice about going to Journalism School. One, there's the employment part. But I wasn't thinking about it in those terms. But the second is that, I felt like it was a little disorienting to be moving from one country to another chasing stories. Finally, the third part, the last point, is that I felt that you can only go so deep as a journalist. You know, you only have one week, two weeks if you're very lucky, to produce a meaningful story. And I felt like that was just merely scratching the surface of things.

ADAMSON: A little thin, maybe sometimes, yeah.

FLORES: Right, very thin, so I felt like if I became a sociologist I could actually stay longer and try to research things on a deeper level. The other factor that brought me to sociology was studying immigration. So I said okay: who studies immigration? That's a topic that I care about. Well, it is sociology! But, I have to tell you something, which is that I went to law school in Mexico City, and I took sociology classes there, but the sociology that we take there is absolutely different from mainstream U.S. sociology.

\section{ADAMSON: How so?}

FLORES: Sociology there is like a branch of philosophy almost. You mostly read these arcane books--you know we read Weber--and so it was not really empirical, or at least the sociology that I was exposed to in college. So I thought it was a very philosophical endeavor, but when I came to the U.S., I became exposed to a different sociology that was on-theground, interested in pressing social issues, and trying to understand social mechanisms. And that really attracted me, trying to understand things at a deep level. It was what convinced me. When I was at Berkeley I had two main advisors. One of my wonderful advisors, Lydia Chavez, was in the J-School, and she was essentially presenting this alternative route. I learned a lot working with her. Chasing the story. Never giving up. Digging until you find the bone! She also taught me to write. My other Berkeley mentor was Irene Bloemraad and I'm always thankful to her because when I was an undergrad there, she kind of took me under her wing despite the fact that at that point she was on the tenure track and had a family. But she made time for me. 
ADAMSON: Right.

FLORES: And I started to develop this idea for an undergraduate thesis on local anti-immigrant policies, but I was not even a Soc major, I just showed up to her office once, or twice, actually...

ADAMSON: Talk to me.

FLORES: Yes, exactly. Adopt me! And she did. When I was in Berkeley, there were all these towns and municipalities that decided to pass anti-immigrant laws. Some of these communities would say, “you know, there's a bunch of Ecuadorians here and we're going to ban volleyball” because Ecuadorians were playing volleyball, right? Some policies were pretty symbolic, but others were more tangible like setting up fines against employers or landlords of immigrants. These policies spread like wild fire. I mean, it was all over the news, so I said, "You know what, I've been to all those places, I've been to El Salvador, I've been to Guatemala, Costa Rica. I want to go to one of these towns in the U.S. and I want to live there. I want to move there. I want to talk to people first-hand. I want to understand: why does a certain town decide to turn against a portion of its residents?” So I began talking with Irene and other folks who were teaching there like Andy Barlow. They said, "you need to go to the town where everything began" and that place was Hazleton, Pennsylvania.

\section{ADAMSON: Uh-huh.}

FLORES: Hazleton was one of the first towns to legislate against immigrants, and it was this big media explosion, where people from as far away as Japan would come and try to understand what was happening. So I got research grants and I got an apartment, I rented a car, and a recording device, much like the one you're using right now, and took notes. I just moved there. I spent a summer there trying to understand this situation from the perspective of longtime residents. That's what I was really interested in. All those interviews that I did there became the foundation for my dissertation later on. When I went to Princeton I wanted to work on understanding the consequences of these anti-immigrant laws on a wider scope. It's 
funny because now people tend to think of me as a quantitative scholar, but I really--this is going to sound like a little feel good commercial --but I really feel like there's a beauty and there's a lot to be gained from doing mixed methods because I learned a lot in Hazelton. I learned a lot. It was not the most pleasant experience for multiple reasons, but it taught me a lot. Even today when I'm thinking about different projects, I still go back to my Hazleton notes. That's why today, when graduate students come to my office and they're like, “Oh, I found this cool new data set and I'm gonna start running things to see what I find!” For me, I feel like you have to get out there and try to understand what's going on, which may actually help you come up with new hypotheses that weren't in the literature. You might be able to go beyond common sense, but I think sometimes grad students rush too much and run correlations to try to see if they find anything interesting, but in my own work, I have seen the power of qualitative research.

ADAMSON: Right, so you think the qualitative, sort of grounding that you had at that level was a necessary base before moving into more quantitative work or just a complimentary?

FLORES: Oh, absolutely I think it was...I was really interested in anthropology. I wanted to be like Malinowski on the Trobriand Islands though now we know his work had a dark side. But back then, I was coming from this anthropological mindset when I went into sociology at Princeton. So I was deeply suspicious of quantitative methods--I had an almost political critique of them. I felt like they were the tools of colonial powers bent on exploiting the little people or something; I had this deep-set suspicion of them, but then after a while I came to realize that these methods are not problematic in themselves, but in how they are used. When you learn something--let's say you learn how to use a hammer--and then you're like, “OK, this is all I have," and then you go around trying to bang on things because all you have is a hammer. But reality is more complex than a bag of nails, right? So, for me, I just saw it as a way to acquire a new tool. Again, you learn how to design experiments or run regressions. That's great, but it doesn't mean that all you should do is experiments and regressions. Some questions may actually require you to interview someone or may actually 
require you to do fieldwork. It all depends on the question. I ended up becoming, essentially, more driven by the question, which I know it absolutely sounds like a cliché, but in my case, that's definitely been the case.

ADAMSON: So what was the question that first, that you had that first drove you to use more quantitative methods? How did your question shift in a way that drove you there?

FLORES: There were several things. One is wondering if the social processes I observed in Hazleton could be happening elsewhere. But there were other puzzles I could not answer with qualitative data. I mean, in Hazleton some local politicians viewed the anti-immigrant laws they proposed as a way to pacify locals. They would say, "You know what, people are worked up about immigration! Just throw them a bone and then they'll just calm down for a minute," right? But by using other kinds of data like twitter data, I find that the opposite actually happens. People become even more worked up, more invested in anti-immigrant activism, which is sort of a counterintuitive finding. With the qualitative data that I used, there were some limitations when I tried understanding the effect of the anti-immigrant law. I arrived to Hazleton a few months after the law had already been proposed. So I had to rely on retrospective data, which meant asking respondents essentially, "what were you doing in the months before the law was passed?" "How did you feel about immigrants then?” I tried multiple ways to get around potential biases like memory limitations or how their political views may have shaped their responses. I tried to do that, but I don't think it was absolutely $100 \%$ guaranteed that I was successful in doing so. But with quantitative data, I could. And that's why I turned to Twitter data. I have a paper about trying to understand if Hazleton can happen at a much wider context, such as in the whole state of Arizona. In Arizona they also passed a highly punitive, highly visible anti-immigration law named SB 1070. And so with Twitter data, I was able to see how people talked about immigrants before and after the law was implemented. In this way, I was able to address memory or politicization biases. In other words, quantitative methods allowed me to tackle the puzzles I discovered during my 
fieldwork in a different way. This allowed me to actually build upon this previous research in a way that I found satisfying.

ADAMSON: I was going to go right to that paper, too, so that was perfect. So, that paper was the "Do Anti-Immigrant Laws Shape Public Sentiment," right? So in that paper you're arguing that policies are more likely to influence behaviors than attitudes?

FLORES: Right.

ADAMSON: And so you use these Twitter posts from Arizona and Nevada for the paper and the posts in lieu of survey data that can tell you more about sentiment, right? So, you already kind of touched on it when you talked about how you got to that, but can you talk about this methodological approach? Going forward, to what extent these findings could be extended beyond the study area there? It seems like you were bringing them from Hazelton to the Arizona and Nevada area, to get a more national picture.

FLORES: The thing about the Hazleton project is that I wasn't able to distinguish between behaviors and attitudes. For me, after being on the ground it kind of seemed like attitudes got shifted. Because people were telling me things like, "the bill was passed and I'm writing letters to my congress people. I think immigrants are vandalizing this town. I've been going to anti-immigrant protests and marches." So for me, I felt like that was an expression of changes in their internal beliefs. But I had no way to disentangle attitudinal from behavioral changes. But with Twitter data, I was actually able to do. I found that the average Tweet about immigrants in Arizona did become more negative after SB 1070. And then, like a hound, I tried to discover the mechanisms that explained that correlation. What I found is that more negative Tweets about immigrants were not driven by people changing their attitudes towards immigrants. If you were anti-immigrant, you remained anti-immigrant after the law was passed. Same thing with pro-immigrant folks. They remained pro-immigrant. Rather, it was a behavioral mechanism: antiimmigrant people began to Tweet more after the law was passed. So, I thought it was a really interesting finding that surprised me initially. Actually, when I first saw that there was no attitudinal 
change I was a bit alarmed. I was like, "what the Hell is going on here?” But I think that's the beauty of social research. You never know what you are going to find. There are two things that I try to do in that paper. First, there is the sentiment analysis part, analyzing text in a systematic way, but the other one, which is a big concern of mine, is causal inference. For me it's really important to not only test if two things, like immigration and crime, are correlated. What I also care about is whether one is causing the other. And that's what I tried to do in that paper. I think a lot of folks that are doing computational analysis, particularly in computer science, are not as preoccupied with causal inference. And I think a lot of economists or political scientists that are more subscribed to causal inference approaches haven't fully explored the possibilities of computational methods, so I thought it was a good way to marry these two methodological approaches. Can we try to make some kind of causal claim using this specific approach? I think that right now I see text analysis exploding because there are so many different possibilities for sociologists. If you care about history, for example, there are so many historic documents, often in the Internet, that can be analyzed computationally. I really think the internet is changing things. Duncan Watts expects the Internet to play the same role for the social sciences as what the telescope did for the harder sciences. I think it's revolutionizing the way we do social research. In my case, I use the Internet to gather data. For example, I do survey experiments and many times I recruit people online. But I'm also collaborating now with a team from the Max Planck Institute in Germany in a project using Facebook data to assess immigrant assimilation. I do it not because I have some kind of fetish--I need to have that golden object--but just because I think the Internet allows a particular kind of insight into human behavior. But there's another thing I want to say, which is that I think these methods shouldn't be the only thing that we pursue. I mean, I'm an experimentalist, but I think that we shouldn't give up on other things. I think we should continue to do demographic research, and we should continue to do descriptive regression-based research because that's the beauty of being a sociologist, right? That you have this arsenal of tools and you can unearth new findings by combining these methods in creative ways. But, sometimes you go to these conferences, particularly I've seen this with experimentalists, not in sociology though but in other 
disciplines. They sometimes talk about experiments almost like a crusader would--there's religiosity there. "This, all of us should be doing this!” And I feel like: "Not necessarily.” I do multiple things, I do descriptive analysis all the time too. So I really see these methods as being additive as opposed to replacing something else. But I think if I were in grad school right now, I would definitely try to pick up these methodological skills, absolutely. I mean that's one of the things you learn in grad school. As a professor, you have less and less time to actually pick them up.

ADAMSON: Yeah.

FLORES: It doesn't mean you have to pick up every single tool in the shed, nobody does that, right? I mean you can, but you're going to get lost in some kind of crazy, methodological maze. But I really feel like this is the time. You have time. Let's say that you're not fully comfortable with regression, just go for it. Think about a paper you can do using regression analysis. It doesn't hurt to learn new things.

ADAMSON: More things in the tool belt.

FLORES: Exactly.

ADAMSON: Something else I'm interested in: it sounds like as a journalist you were doing international work too, so maybe that's the answer, but you've gone to Spain to look at the resurgence of race. Can you talk to me a little bit about your reasons for moving into the European context for migration research? How does that complement your work in the United States?

FLORES: Because I'm a masochist, that's why [laughing]. I mean I think part of that is because I have an international background. So maybe for me, it just feels natural to expect cultural differences, and I think in the U.S. we're a little bit provincial in the sense that many assume sociology is whatever happens in the U.S. I remember when I was trying to publish that paper you mention on perceived discrimination by immigrants in Spain. It was published in Social Forces. But it got rejected from a different journal before. One of 
the reviewers actually said: "Why should we care about Spain? I mean, what's interesting from a sociological perspective about Spain?” For me that was self-evident, but I think what the reviewer was actually asking was, "It's not the U.S. so why should we care about it?" I mean, in sociology the list of countries that you can actually publish on without being asked this question is relatively short: the U.S., Mexico, Brazil, France, Germany, maybe China. The big irony is that I published a paper that is based on a single Pennsylvania town, Hazleton, and nobody asked me, "Why should we care? Does this apply to anything else beyond Northeastern Pennsylvania?” So I feel like there's a lot of work to be done to expand the accepted boundaries of sociological inquiry. I really feel like it only makes sense to try to understand whether the sociological theories that we created and tested in the U.S. case apply to other societies. Think about immigration. Some of these theories and research go back to the Chicago school of Sociology, for example, but do they apply to other societies? For example, are African descendants always at the bottom of the social hierarchy? Based on the U.S. case, we assume that skin color is going to have a negative effect on all different outcomes, and that the darker you are, the worse off you'll be, but is that really the case in other places? Maybe the correlation is the opposite way in other cases; maybe there are other elements that enter into the equation, and that's why I wanted to study the case of Spain, which is really interesting. When I talk about that paper to my undergrads or give talks, people are very surprised when I tell them how different things are. For example, I ask them "who do you guys think is the most suspected or the least liked group in Spain?" And most of them will say, "Is it Africans? Is it South Americans?” and I say, "No, in many cases, it's Eastern Europeans.” They're really shocked because that doesn't necessarily jive with the U.S. experience. So those are things that makes us question what we know about immigrant adaptation and the things that we know about race and racialization. Are those contexts dependent? Is the validity of these theories contingent upon a specific political system or a specific historical context? That's a huge question. 
ADAMSON: That is a huge question. Do you think you'll continue doing comparative, or international work to test those, to test the theory there?

FLORES: I'm actually starting to look more at Latin America. So I have a couple of papers about trying to understand race and ethnicity in Latin America, so yeah, I see myself as doing comparative work within the Western world, you know within Europe, Latin America, and the U.S. I haven't ventured outside of the West because I think you have to know something about the places that you study before you actually start doing something there. But I'm very attracted to international research. Absolutely.

ADAMSON: So what lessons do you think you want people to take away from your research? What kind of impact do you hope your research is having?

FLORES: Well, I guess I'm trying to illuminate the social forces that shape the lives of marginalized groups. I mean I think if we develop a deeper understanding of that, we could potentially try to devise public policies to address these situations. For example, for the project on illegality that I'll be presenting today, which I did in collaboration with my fabulous colleague, Ariela Schachter at Washington University in St. Louis, we wanted to understand the social stereotypes that are driving perceived illegality. We're essentially arguing that illegality is a very complex status, you know? Most people haven't had a legal or immigration training to determine who's so called "illegal” and who's not. So, we believe they rely on social stereotypes to try to determine that. We coined the term "social illegality" to refer to the process through which certain bodies are classified as legal, regardless of their actual documentation status. And we believe that social illegality may have negative consequences for people that fit the profile and conform to these pervasive social stereotypes. So we believe that this kind of work can not only potentially help the majority group to understand that there are certain biases that we need to be more aware of, but we are also trying to inform the ways in which immigrant communities actually approach their own political activism, essentially to understand what they're up against. So, it's a two-way 
process there. Having a public policy impact in immigration is tough, but hopefully we can influence the discourse around it. That would be good.

ADAMSON: Thanks for your time, we appreciate you talking to us this morning.

FLORES: My pleasure. 